\title{
Penerapan Convolutional Neural Network (CNN) pada Pengenalan Aksara Lampung Berbasis Optical Character Recognition (OCR)
}

\author{
Agus Mulyanto $^{\# 1}$, Erlina Susanti ${ }^{\# 2}$, Farli Rosi ${ }^{\# 3}$, Wajiran ${ }^{\# 4}$, Rohmat Indra Borman ${ }^{\# 5}$ \\ \#Fakultas Teknik dan Ilmu Komputer (FTIK), Universitas Teknokrat Indonesia \\ Jl. H. Zainal Abidin Pagaralam No. 9 - 11 Labuhan Ratu, Bandar Lampung \\ ${ }^{1}$ agus.mulyantoeteknokrat.ac.id \\ 2erlnssnti13@gmail.com \\ ${ }^{3}$ farlirosi@teknokrat.ac.id \\ ${ }^{4}$ wajiran.wajiraneteknokrat.ac.id \\ ${ }^{5}$ rohmat indraeteknokrat.ac.id
}

\begin{abstract}
Abstrak - Provinsi Lampung memiliki bahasa dan aksara daerah yang disebut juga dengan Had Lampung atau KaGaNga yang merupakan aksara asli lampung. Melihat bagaimana pentingnya nilai akan eksistensi sebuah budaya dan pentingnya pelestarian aksara lampung maka dibutuhkan teknologi yang membantu dalam mengenalkan aksara lampung, salah satunya dengan teknologi optical character recognition (OCR) yang digunakan untuk merubah citra kedalam teks. Untuk mengenali pola citra Aksara Lampung dan klasifikasi model maka digunakan Convolutional Neural Network (CNN). CNN memiliki lapisan convolution yang terbentuk dari beberapa gabungan lapisan konvolusi, lapisan pooling dan lapisan fully connected. Pada peneilitian yang dilakukan dataset dikembangkan dengan pengumpulan hasil tulis tangan dari sampel responden yang telah ditentukan, kemudian dilakukan scanning gambar. Selanjutnya, dilakukan proses pelabelan dan disimpan dengan format YOLO yaitu TXT. Dari asitektur CNN yang dibangun berdasarkan hasil evaluasi menunjukan loss, accuracy menghasilkan nilai training accuracy mendapatkan nilai sebesar 0.57 dan precision mendapatkan nilai sebesar 0.87. Dari hasil nilai accuracy dan precision menunjukkan bahwa model training sudah baik karena mendekati angka 1.
\end{abstract}

Kata kunci- aksara lampung, computer vision, cnn, deep learning, ocr

\section{Pendahuluan}

Indonesia mempunyai budaya yang sangat beragam, daiantaranya kesenian, tatanan bahasa sampai dengan tingkah laku masyarakatnya. Salah satu budaya berupa tatanan bahasa adalam tulisan atau biasanya disebut dengan istilah aksara. Lampung adalah salah satu provinsi di Indonesia yang terdapat bahasa daerah dan aksara daerah. Aksara Lampung disebut juga dengan Had Lampung atau masyarakat Lampung menyebut dengan istilah KaGaNga, merupakan aksara asli lampung dengan teknik penulisan yang membacanya diawali kiri kemudian ke kanan dengan huruf induk dengan sejumlah 20 huruf [1]-[3]. Had Lampung dirangkai melalui kalimat dengan digabungkanya induk aksara dengan anak aksara. Anak aksara terdiri dari 12 buah yang dimungkinkan untuk diletakkan diatas, dibawah, dikiri dari induk aksara. Had Lampung mempunyak keunikan tersendiri dari segi bentuknya, akan tetapi minat dari masyarakat terhadap aksara dinilai rendah. Usaha yang dilakukan untuk menjaga dan melestarikan kebudayaan daerah bukan hanya tanggungjawab pemerintah pusat akan tetapi dibutuhkan peran aktif masyarakat dan institusi pendidikan serta lembaga pendidikan [4]. Melihat bagaimana pentingnya nilai akan eksistensi sebuah budaya dan pentingnya pelestarian aksara lampung maka dibutuhkan teknologi yang membantu dalam mengenalkan aksara lampung kepada masyarakat. Salah satunya dengan teknologi optical character recognition (OCR) yang dapat dipergunakan untuk merubah citra kedalam teks agar dapat mebantu masyarakat untuk mengenal aksara lampung dengan lebih mudah. OCR merupakan sebuah aplikasi yang dapat menerjemahkan image character kedalam bentuk teks melalui penyesuaian pola-pola dari karakter setiap barisnya terhadap pola yang terdapat pada penyimpanan di sistem [5]. OCR dapat digunakan untuk membantu menyelesaikan masalah dalam mengekstraksi informasi atau pembacaan tulisan dalam bentuk image [6]. Proses dalam pengembagan OCR yang harus diperhatikan adalah mengekstrak ciri dan mengenali pola. Ekstraksi ciri bertujuan agar didapatkan ciri atau identitas dari sebuah karakter [7]. Sedangkan pengenalan pola memiliki fungsi sebagai pencocokan pola berdasarkan pada inputan dengan pola yang ada dalam knowledge base [8].

Untuk mengenali pola dan klasifikasi model yang dilatih dapat menggunakan pendekatan deep learning. CNN digunakan pada bidang visi komputer dalam pengklasifikasian gambar dan pengenalan objek. CNN 
menggambarkan variasi dari multilayer perceptron yang dapat beroperasi pada data dua dimensi dengan cara kerja mirip dengan jaringan syaraf yang ada pada manusia [9]. CNN menunjukkan kinerja yang menonjol dalam penglasifikasian citra, anotasi gambar, dan berbagai bidang visi komputer lainya [10][11]. CNN mampu mengenal karakter baru yang sebelumnya tidak ada dalam dataset dan dapat melakukannya dengan lebih ringkas [12]. Hal ini disebabkan pada CNN terdapat feature extraction layer.

Penggunaan CNN pada OCR pada penelitian sebelumnya menunjukkan hasil yang baik. Pada penelitian tentang pengenalan aksara Jawa dengan pendekatan CNN berdasarkan hasil pengujian terhadap data testing Aksara Jawa mendapatkan tingkat akurasi mencapai 95,04\% [13]. Citra yang tersegmentasi akan jadi sebuah input pada fitur ekstraksi dan klasifikasi. Kemudian citra tersebut disegmentasi dan dilakukan training menggunakan CNN. Peneyelesaian ekstraksi pada fitur dalam deep learning (CNN) tergantung pada proses konvolusi bekerja. Penelitian yang lain, tentang deteksi ujaran kebencian pada gambar dengan OCR yang penyelesainya menerapkan CNN. Pada proses pengujian performa asitektur yang dikembangkan mendapatkan nilai precision dengan hasil 99.46\%, recall sebesar 97.99\%, serta accuracy dengan nilai 99.8\% [14]. Pada penelitian ini, menyimpulkan bahwa semakin banyak data train yang dilakukan maka tingkat accuracy akan semakin baik. Diketahui juga bahwa jumlah dari filter serta ukuran dimensi dapat berpengaruh pada tahapan training dan mempengaruhi hasilnya. Selain itu ukuran epoch dan batch size juga berpengaruh terhadap performa dan hasil dari akurasinya. Penelitian selanjutnya, tentang transliterasi aksara jawa tulisan tangan ke tulisan latin menggunakan $\mathrm{CNN}$, proses pembelajaran mendapatkan akurasi 0,9962 sedangkan saat testing menghasilkan akurasi $80 \%$ dengan 20 citra uji [15]. Dari hasil ini terbukti bahwa CNN merupakan pendekatan yang tepat untuk penyelesaian pada pengenalan pola.

Dalam penelitian ini akan melakukan pengenalan aksara Lampung menggunakan metode CNN dan pembuatan dataset aksara lampung yang terdiri atas 226 kelas. Bentuk luaran dari penelitian ini akan menghasilkan model cerdas yang dapat dimanfaatkan untuk OCR pengenalan aksara lampung.

\section{METODE}

Untuk mengenali pola citra Aksara Lampung dengan Optical Character Recognition (OCR) menggunakan Convolutional Neural Network (CNN) terdapat beberapa tahapan dalam penelitian ini. Gambar 1 merupakan tahapan penelitian yang akan dilakukan, berikut dengan penjelasan setiap tahapanya.

\section{A. Pengumpulan Dataset}

Pada penelitian ini mendapatkan dataset dengan cara mengumpulkan repsonden diminta untuk menulis aksara Lampung. Jumlah data yang didapatkan sebanyak 53.764 buah gambar aksara lampung, dimana terdapat 20 induk huruf jenis aksara lampung dasar dengan kombinasi 12 anak huruf, sehingga setiap jenis aksara memiliki data gambar sebanyak 226 buah. Citra diambil pada sebuah lembaran kertas putih yang ditulis dengan menggunakan tinta hitam dan biru. Tulisan aksara lampung tersebut akan ditulis oleh 100 orang penulis yang berbeda dimana satu orang menulis 5 lembar kertas aksara lampung. Citra Aksara Lampung yang telah didapatkan selanjutnya terbagi menjadi dua diantaranya: data training dan data testing. Data training adalah sebuah data yang berguna untuk pelatihan pada model. Kemudian data testing dipergunakan untuk uji model, yang berguna untuk mensimulasikan penggunaan model pada dunia nyata. Rasio pembagian yang digunakan adalah 70:30 persen dimana 70\% untuk training yaitu sebanyak 38.334 gambar, $30 \%$ untuk testing yaitu sebanyak 16.428 gambar.

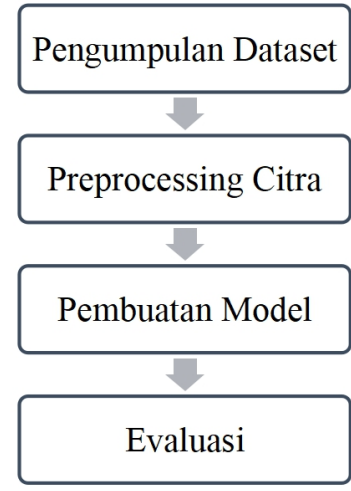

Gambar. 1 Tahapan penelitian

\section{B. Preprocessing Citra}

Setelah dataset dikumpulkan, selanjutnya dilakukan beberapa tahapan preprocessing. Tahapan ini merupakan tahap yang penting sebelum dilakukanya klasifikasi [16]. Tujuan dari tahpan ini adalah untuk membuat data berupa citra agar jadi lebih baik apabila dilakukan proses ekstraksi fitur [17]. Pada tahap ini akan dilakukan cropping, gray scaling dan thresholding. Cropping dilakukan dengan cara manual melalui aplikasi Snipping Tool. Peoses ini bertujuan untuk menghilangkan sisi yang tidak diperlukan, selain itu untuk mengurangi jumlah baris. Sedangkan gray scaling untuk merubah image menjadi skala keabuan. Kemudian, thresholding berguna dalam memberikan nilai biner dari image.

\section{Pembuatan Model}

Penelitian yang akan dilakukan akan menggunakan model CNN. CNN merupakan pendekatan deep learning yang bisa dipergunakan dalam klasifikasi citra, dikelompokkan didasarkan pada kesamaan, dan mampu melakukan pengenalan adegan [18]. CNN memiliki lapisan convolution yang terbentuk dari beberapa gabungan lapisan konvolusi, lapisan pooling dan lapisan fully connected. Arsitektur CNN terlihat seperti pada gambar 2, yang menunjukkan $\mathrm{CNN}$ mempunyai beberapa 
jenis layer yang dapat digunakan yaitu subsampling layer, convolutional layer, loss layer dan fully connected layer.

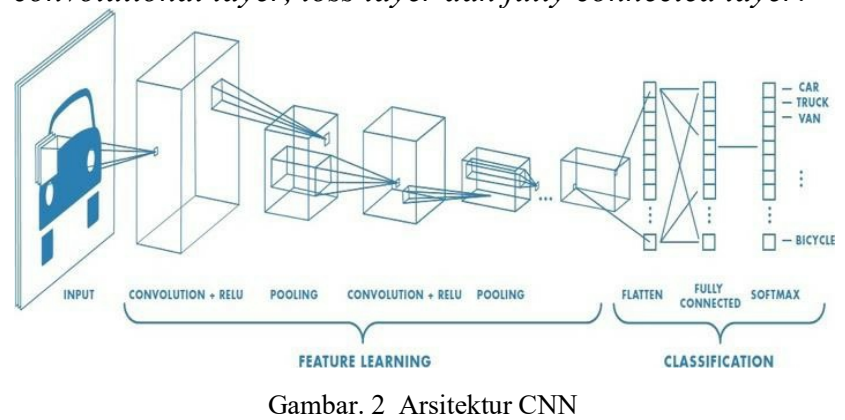

CNN yang akan diimplementasikan tidak menggunakan banyak lapisan, hal ini bertujuan agar dapat menghemat waktu training. Arsitektur CNN yang sederhana sudah dirasa mencukupi untuk menyelesaikan klasifikasi citra dengan dataset yang relatif sedikit, mengingat kategori untuk klasifikasi hanya sedikit. Adapun sedikitnya jumlah data yang digunakan untuk pembelajaran dan diprediksi akan dihasilkan akurasi yang kurang maksimal. Teknik ini diimplementasikan dalam pendekatan $\mathrm{CNN}$ yang akan berpengaruh pada kinerja model pada pelatihan sehingga overfitting dapat berkurang [19].

\section{Evaluasi}

Pengukuran kinerja klasifikasi pada umumnya menggunakan confusion matrix, yang merupakan matrik $2 \times 2$ yang mendiskripsikan hasil dari klasifikasi biner sebuah set data [20]. Tabel 1 memperlihatkan deskripsi sederhana mengenai confusion matrix.

TABEL I

CONFUSION MATRIX

\begin{tabular}{|c|c|l|l|}
\hline \multicolumn{2}{|c|}{} & \multicolumn{2}{c|}{ Kategori Prediksi } \\
\cline { 3 - 4 } \multicolumn{2}{|c|}{} & Positif & Negatif \\
\hline \multirow{2}{*}{$\begin{array}{c}\text { Kategori } \\
\text { Aktual }\end{array}$} & Positif & TP & FN \\
\cline { 2 - 4 } & Negatif & FP & TN \\
\hline
\end{tabular}

Dari Tabel 1, True Positif (TP) menunjukkan data yang terprediksi benar dan dan hasil prediksi benar. True Negatif (TN) merupakan data hasil prediksi yang salah dan hasil prediksi salah. False Positif (FP) merupakan data terprediksi yang salah akan tetapi prediksi hasilnya benar. Sedangkan False Negative (FN) menunjukkan data hasil prediksi benar akan tetapi prediksi yang dihasilkan salah. Nilai yang dihasilkan berupa accuracy, precision dan recall. Accuracy merupakan evaluasi berdasarkan jumlah proporsi prediksi yang benar [20]. Accuracy dapat diukur dengan persamaan berikut ini:

Accuracy $=\frac{T P+T N}{T P+F P+T N+F N}$

Selanjutnya, precision merupakan proporsi jumlah yang relevan dapat dikendalikan dari semua yang terpilih [20]. Berikut formula menghitung presisi.

Precision $=\frac{T P}{T P+F P}$
Sedangkan recall merupakan proporsi jumlah yang relevan dapat dikendalikan dari semua yang relevan [21]. Berikut ini formula yang digunakan untuk mengukur recall.

Recall $=\frac{T P}{T P+F N}$

Data yang digunakan merupakan hasil prediksi dengan data test sebesar 583 gambar dimana terdapat 226 kelas, cara menentukan kelas yang benar dan salah menggunakan looping prediksi sehingga gambar hasil prediksi akan dimasukkan kedalam folder prediksinya.

\section{HASIL DAN PEMBAHASAN}

Untuk mengembangkan pengenalan Aksara Lampung dengan OCR langkah awal citra yang sudah didapatkan selanjutnya dilakukan pelabelan. Pelabelan gambar merupakan tahap dimana dataset input diberikan label dengan tujuan untuk menyimpan informasi gambar yang selanjutnya disimpan dalam berkas TXT dengan format YOLO. Pelabelan dilakukan secara manual terhadap 53.764 gambar. Pelabelan dilakukan dengan cara memberi nama kelas pada setiap objek agar dapat dikenali ketika proses training. Kemudian dari hasil pelabelan tersebut didapatkan 53.764 bounding box yang terdiri dari 226 kelas.

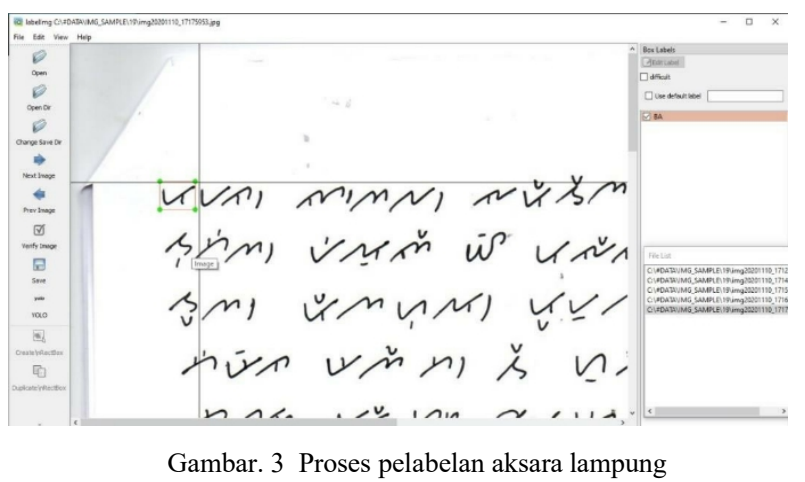

Arsitektur CNN yang dikembangkan bertujuan untuk klasifikasi citra Aksara Lampung dengan baik. Model CNN yang dikembangkan dapat terlihat di Gambar 4.

Asitektur CNN tersebut kemudian dimplementasikan pada Google Colab pada laman berikut https://colab.research.google.com. Langkah awal yang dilakukan adalah ekstraksi data yang berupa gambar digital yang diambil dari folder kemudian dikonversi ke array yang bisa terbaca pada Tensorflow, code fungsi yang digunakan yaitu sebagai berikut:

From tensorflow. keras. preprocessing. image import ImageDataGenerator

Fungsi ini merupakan Image data generator sehingga dapat mengenerate data image atau gambar. Selanjutnya membuat base model yaitu dengan mendefinisikan terlebih dahulu model yang akan digunakan. Yang perlu diperhatikan pada base model adalah menentkan Include 
top. Include top merupakan perintah untuk disertakanya model yang diimplementasikan dapat ditambahkan menggunakan top layer dari sebuah network yang ada. Misalkan top network dari model yang ada mempunyai node diantaranya: flatten layer, layer dengan node sebanyak 1024 dan fungsi aktivasinya, kemudian prediction node dengan jumlah node sesuai dengan jumlah dari kelas. Karena jumlah kelasnya 1000 maka terjadi ketidaksesuaian dengan kelas yang berjumlah hanya 5, maka include top bernilai false.
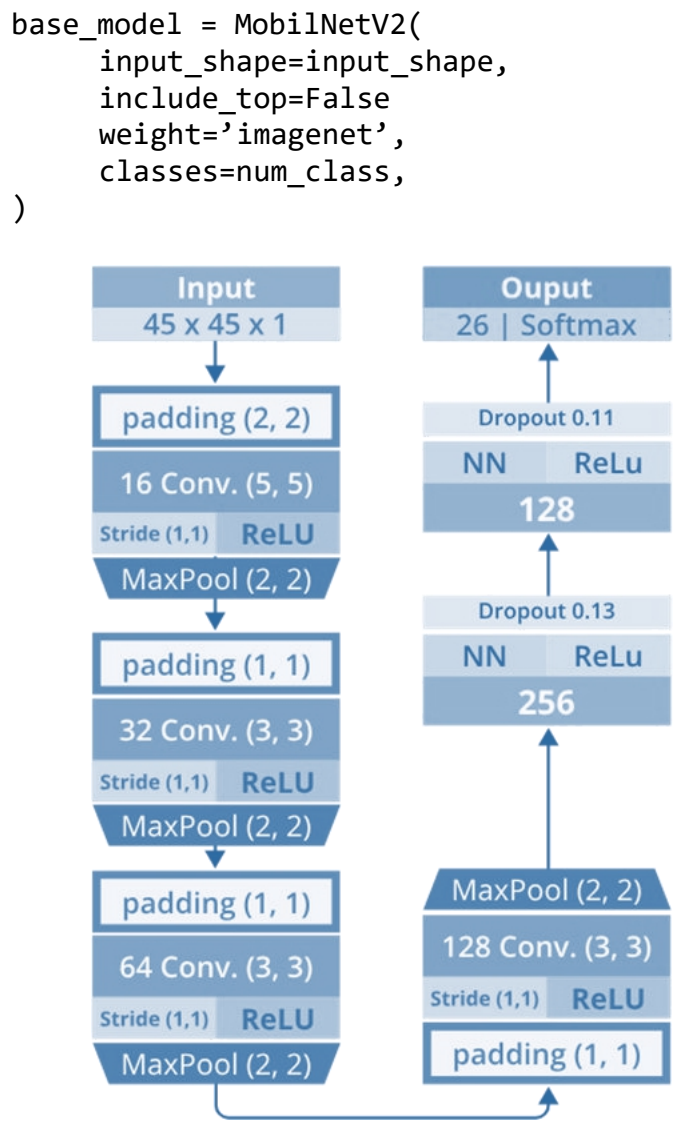

Gambar. 4 Asitektur CNN yang dikemabgnkan

Apabila model telah dibangun, langkah selanjutnya dilakukan tahapan training. Proses training adalah salah satu proses pembelajaran mesin dapat bekerja maka metode yang sudah terdefinisi sebelumnya dapat mengingat pola dari setiap kelas pada data training. Proses training dapat dilihat pada Gambar 5.

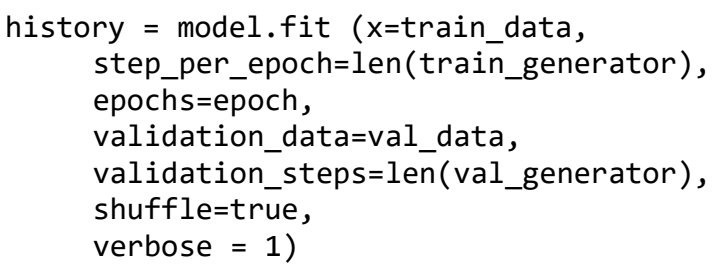

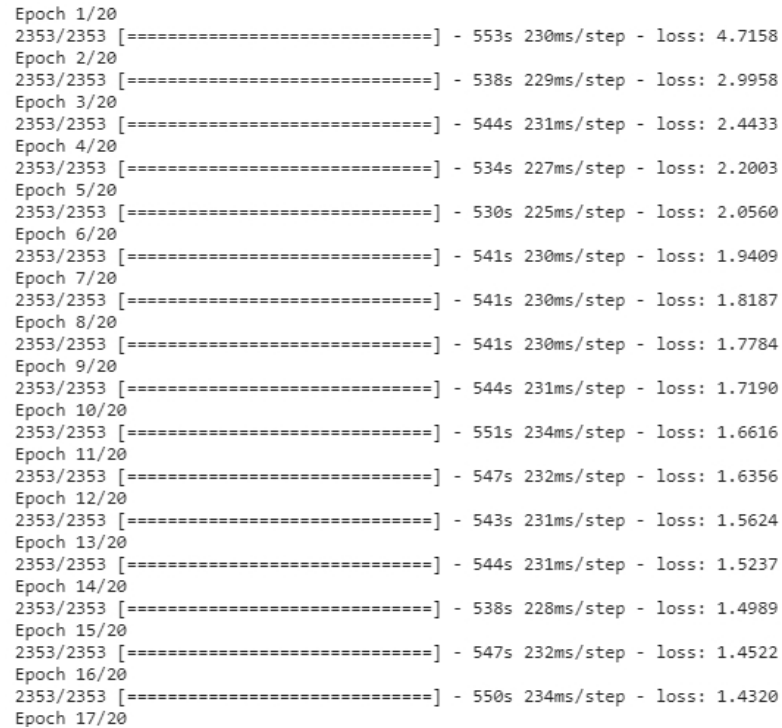

Gambar. 5 Proses training

Loss menunjukkan seberapa buruk prediksi model pada yang dilakukan. Jika prediksi model sempurna, maka loss bernilai nol, sebaliknya jika nilai loss besar maka maka model tidak efektif. Tujuan dari melatih model adalah untuk menemukan sekumpulan bobot dan memiliki nilai loss yang rendah. Training loss yang didapatkan pada training loss grafik loss hasil akhir: Training loss sebesar 1.6 dengan validation loss sebesar 5.2 dapat dikatakan training loss hasil akhir rendah. Training dan validation loss dapat dilihat pada Gambar 6. Selanjutnya evaluasi dilakukan berdasarkan nilai accuracy, precision dan recall. Hasil Evaluasi dapat dilihat pada Tabel 2.

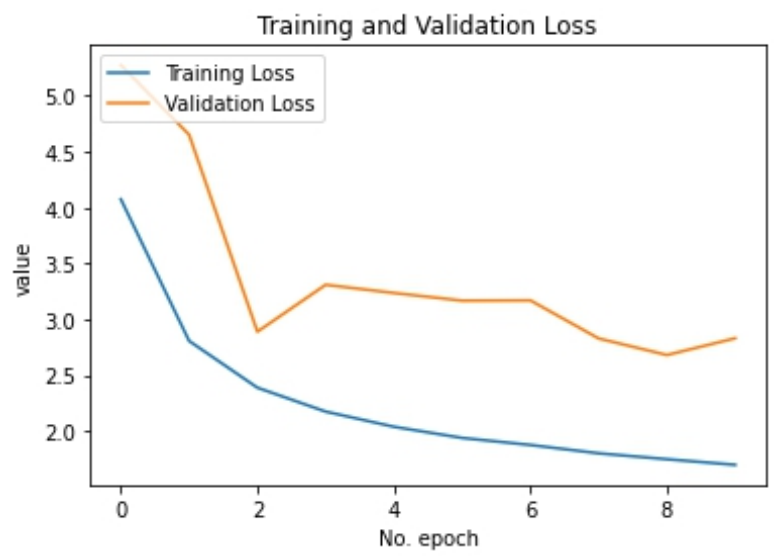

Gambar. 6 Training dan Validation Loss

TABEL II

HASIL EVALUASI

\begin{tabular}{|c|c|c|c|c|c|}
\hline \multicolumn{2}{|c|}{ Accuracy } & \multicolumn{2}{c|}{ Precision } & \multicolumn{2}{c|}{ Recall } \\
\hline $\begin{array}{c}\text { Trainin } \\
\mathrm{g}\end{array}$ & $\begin{array}{c}\text { Validati } \\
\text { on }\end{array}$ & $\begin{array}{c}\text { Trainin } \\
\mathrm{g}\end{array}$ & $\begin{array}{c}\text { Validati } \\
\text { on }\end{array}$ & $\begin{array}{c}\text { Trainin } \\
\mathrm{g}\end{array}$ & $\begin{array}{c}\text { Validati } \\
\text { on }\end{array}$ \\
\hline 0.57 & 0.32 & 0.87 & 0.58 & 0,47 & 0.09 \\
\hline
\end{tabular}


Pada Tabel 2 untuk accuracy menghasilkan nilai training accuracy mendapatkan nilai sebesar 0.57 dan validation accuracy mendapatkan nilai sebesar 0.32 , nilai mendekati angka 1 maka accuracy dapat dikatakan baik Pada nilai precision dihasilkan training precision mendapatkan nilai sebesar 0.87 dengan nilai validation precission sebesar 0.58 , ini menunjukkan bahwa model training baik karena mendekati angka 1 . Untuk recall didapatkan nilai training recall $=0.47$ validation recall $=$ 0.09 yang menandakan bahwa hasil model rendah, hasil model yang rendah terjadi karena saat melakukan penyebutan label ada ketidasesuaian saat pelabelan dianotasikan sehingga dimana annotator mesin gagal membuat anotasi yang seharusnya ada. Setelah model di evaluasi, maka selanjutnya dilakukan prediksi. Pada proses ini dilakukan pemotongan atau croping citra dari testing untuk dilanjutkan test predikisi pada gambar yang sudah di crop menggunakan gambar atau dokumen testing sehingga menghasilkan prediksi. Hasil gambar test dapat dilihat pada Gambar 7.

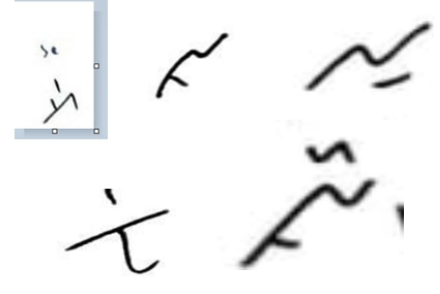

Gambar. 7 Hasil Gambar Test

\section{KESIMPULAN}

Pada peneilitian yang dilakukan pembuatan dataset dilakukan melalui pengumpulan hasil tulis tangan kemudian dilakukan scanning gambar, kemudian untuk tahapan preprocessing dilakukan proses pelabelan dan disimpan dengan format YOLO yaitu TXT. CNN diterapkan untuk klasifikasi citra aksara lampung. Dari asitektur $\mathrm{CNN}$ yang dibangun berdasarkan hasil evaluasi menunjukan loss, accuracy dan precision yang baik. Tetapi untuk hasil recall memiliki nilai yang rendah. Untuk itu saran untuk penelitian kedepan pada penyebutan label dilakukan kesesuaian saat pelabelan dianotasikan sehingga membuat anotasi yang seharusnya ada. Selain itu untuk menghasilkan prediksi yang baik dataset perlu ditingkatkan jumlahnya, karena CNN bergantung dengan jumlah input data yang dapat menghasilkan performa terbaik.

\section{UCAPAN TERIMA KASIH / ACKNOWLEDGMENT}

Peneliti menugucapkan terima kasih kepada "Yayayasan Pendidikan Teknokrat, Universitas Teknokrat Indonesia dan LPPM Universitas Teknokrat Indonesia" yang telah memberikan dukungan terhadap penelitian ini.

\section{REFERENSI}

[1] D. Fitriati, "Pemeriksa Jawaban Tulisan Tangan untuk Ujian Pilihan Ganda Menggunakan Hybrid Extreme Learning
Convolutional Neural Network Machine," J. Media Infotama, vol. 15 , no. 1, pp. 22-28, 2019.

[2] A. Mulyanto, A. Apriyadi, and P. Prasetyawan, "Rancang Bangun Game Edukasi 'Matching Aksara Lampung' Berbasis Smartphone Android," Comput. Eng. Sci. Syst. J., vol. 3, no. 1, p. 36, 2018.

[3] S. Ningsih and S. Saniati, "Eksperimen Pengenalan Ucapan Aksara Lampung Dengan CMU Sphinx 4," J. Teknoinfo, vol. 12, no. 1, p. $33,2018$.

[4] Z. Abidin, "Penerapan Neural Machine Translation untuk Eksperimen Penerjemahan secara Otomatis pada Bahasa Lampung - Indonesia," Pros. Semin. Nas. Metod. Kuantitatif 2017, no. 978, pp. 53-68, 2017.

[5] A. Setiawan, H. Sujaini, and A. Bijaksana Pn, "Implementasi Optical Character Recognition (OCR) pada Mesin Penerjemah Bahasa Indonesia ke Bahasa Inggris," J. Sist. dan Teknol. Inf., vol. 5, no. 2, pp. 135-141, 2017.

[6] H. Oktavianto and H. W. Sulistyo, "Optical Character Recognition Untuk Ekstraksi Teks Rambu Lalu Lintas," JUSTINDO (Jurnal Sist. Teknol. Inf. Indones., vol. 3, no. 1, pp. $15-21,2018$.

[7] R. I. Borman and B. Priyopradono, "Implementasi Penerjemah Bahasa Isyarat Pada Bahasa Isyarat Indonesia ( BISINDO ) Dengan Metode Principal Component Analysis ( PCA )," J. Pengemb. IT, vol. 03, no. 1, pp. 103-108, 2018.

[8] S. Hartanto, A. Sugiharto, and S. N. Endah, "Optical Character Recognition Menggunakan Algoritma Template Matching Correlation," J. Masy. Inform., vol. 5, no. 9, pp. 1-11, 2015.

[9] M. M. Taslim, K. Gunadi, and A. N. Tjondrowiguno, "Deteksi Rumus Matematika pada Halaman Dokumen Digital dengan Metode Convolutional Neural Network," J. Infra, vol. 7, no. 2, pp. 123-129, 2019.

[10] S. M. A. Sharif, N. Mohammed, N. Mansoor, and S. Momen, "A hybrid deep model with HOG features for Bangla handwritten numeral classification," in Proceedings of 9th International Conference on Electrical and Computer Engineering, ICECE 2016, 2017, no. February 2018, pp. 463-466.

[11] A. Mulyanto, R. I. Borman, P. Prasetyawana, and A. Sumarudin, "2D Lidar and Camera Fusion for Object Detection and Object Distance Measurement of ADAS Using Robotic Operating System ( ROS )," vol. 4, pp. 231-236.

[12] W. A. Saputra, M. Z. Naf'an, and A. Nurrochman, "Implementasi Keras Library dan Convolutional Neural Network Pada Konversi Formulir Pendaftaran Siswa," J. RESTI (Rekayasa Sist. dan Teknol. Informasi), vol. 1, no. 10, pp. 524-531, 2019.

[13] C. A. Lorentius, R. Adipranata, and A. Tjondrowiguno, "Pengenalan Aksara Jawa dengan Menggunakan Metode Convolutional Neural Network," e-Proceeding Eng., vol. 7, no. 1, pp. 2558-2567, 2020.

[14] B. P. Putra, B. Irawan, C. Setianingsih, F. T. Elektro, U. Telkom, and D. Learning, "Deteksi Ujaran Kebencian Dengan Menggunakan Algoritma Convolutional Neural Network Pada Gambar," e-Proceeding Eng., vol. 5, no. 2, pp. 2395-2402, 2018.

[15] F. Ilham and N. Rochmawati, "Transliterasi Aksara Jawa Tulisan Tangan ke Tulisan Latin Menggunakan CNN," JINACS, vol. 1, no. 4, pp. 200-208, 2020.

[16] D. Alita, Y. Fernando, and H. Sulistiani, "Implementasi Algoritma Multiclass Svm Pada Opini Publik Berbahasa Indonesia Di Twitter," J. TEKNOKOMPAK, vol. 14, no. 2, p. 86, 2020.

[17] I. G. R. A. Sugiartha, M. Sudarma, and I. M. O. Widyantara, "Ekstraksi Fitur Warna, Tekstur dan Bentuk untuk ClusteredBased Retrieval of Images (CLUE)," Maj. Ilm. Teknol. Elektro, vol. 16, no. 1, p. 85, 2016.

[18] M. M. Saufi, M. A. Zamanhuri, N. Mohammad, and Z. Ibrahim, "Deep learning for roman handwritten character recognition," Indones. J. Electr. Eng. Comput. Sci., vol. 12, no. 2, pp. 455-460, 2018.

[19] N. Srivastava, H. Geoffrey, A. Krizhevsky, S. Ilya, and R. Salakhutdinov, "Dropout: A Simple Way to Prevent Neural Networks from Overfittin," J. Mach. Learn. Res., vol. 15, pp. 345-350, 2014.

[20] L. A. Andika, P. A. N. Azizah, and R. Respatiwulan, "Analisis Sentimen Masyarakat terhadap Hasil Quick Count Pemilihan Presiden Indonesia 2019 pada Media Sosial Twitter Menggunakan 
Metode Naive Bayes Classifier," Indones. J. Appl. Stat., vol. 2, no. 1, p. 34, 2019

[21] P. Prasetyawan, I. Ahmad, R. I. Borman, A. Ardiansyah, Y. A. Pahlevi, and D. E. Kurniawan, "Classification of the Period
Undergraduate Study Using Back-propagation Neural Network," in Proceedings of the 2018 International Conference on Applied Engineering, ICAE 2018, 2018. 